TITLE:

\title{
Direct cyanomethylation of aliphatic and aromatic hydrocarbons with acetonitrile over a metal loaded titanium oxide photocatalyst
}

\section{$\operatorname{AUTHOR}(\mathrm{S}):$}

Wada, Emiko; Takeuchi, Tomoaki; Fujimura, Yuki; Tyagi, Akanksha; Kato, Tatsuhisa; Yoshida, Hisao

\section{CITATION:}

Wada, Emiko ...[et al]. Direct cyanomethylation of aliphatic and aromatic hydrocarbons with acetonitrile over a metal loaded titanium oxide photocatalyst. Catalysis Science \& Technology 2017, 7(12): 2457-2466

\section{ISSUE DATE:}

2017-06-21

URL:

http://hdl.handle.net/2433/230943

\section{RIGHT:}

This is the accepted manuscript of the article, which has been published in final form at

https://doi.org/10.1039/C7CY00365J; The full-text file will be made open to the public on $12 \mathrm{Apr} 2018 \mathrm{in}$ accordance with publisher's 'Terms and Conditions for Self-Archiving'.; This is not the published version. Please cite only the published version.; この論文は出版社版でありません。引用の際には出版社版をご確認ご利用ください。 


\section{Journal Name}

\section{ARTICLE}

\section{Direct cyanomethylation of aliphatic and aromatic hydrocarbons with acetonitrile over metal loaded titanium oxide photocatalyst}

Received 00th January 20xx Accepted 00th January 20xx DOI: $10.1039 / x 0 x x 00000 x$ www.rsc.org/

\author{
Emiko Wada, ${ }^{\mathrm{a}, \mathrm{b}}$ Tomoaki Takeuchi, ${ }^{\mathrm{a}}$ Yuki Fujimura, ${ }^{\mathrm{c}}$ Akanksha Tyagi, ${ }^{a}$ Tatsuhisa Kato ${ }^{\mathrm{a}, \mathrm{d}}$ and Hisao \\ Yoshida*a,e
}

Platinum-loaded $\mathrm{TiO}_{2}\left(\mathrm{Pt} / \mathrm{TiO}_{2}\right)$ photocatalyst promoted cyanomethylation of aliphatic hydrocarbons, namely cyclohexane and cyclohexene, with acetonitrile, where the photogenerated hole oxidatively dissociates the $\mathrm{C}-\mathrm{H}$ bond of both the acetonitrile and the aliphatic hydrocarbons to form each radical species before the radical cross-coupling of them. The $\mathrm{Pt} / \mathrm{TiO}_{2}$ photocatalyst was more active than the $\mathrm{Pd} / \mathrm{TiO}_{2}$ photocatalyst in these reactions. In contrast, the cyanomethylation of benzene was promoted by the $\mathrm{Pd} / \mathrm{TiO}_{2}$ photocatalyst or a physical mixture of the $\mathrm{Pt} / \mathrm{TiO}_{2}$ photocatalyst and a Pd catalyst supported by $\mathrm{Al}_{2} \mathrm{O}_{3}$, while it was hardly promoted by the $\mathrm{Pt} / \mathrm{TiO}_{2}$ photocatalyst alone. The temperature dependence of the reaction rate proved that the $\mathrm{Pd}$ nanoparticles on the $\mathrm{TiO}_{2}$ photocatalyst function as a metal catalyst in the dark process. These results clearly suggest that the Pd metal catalyst is necessary for the cyanomethylation of benzene. However, in the cyanomethylation of aliphatic hydrocarbons, the catalytic effect by the metal particles was not observed, meaning that the radical coupling takes place without the metal catalysis. Thus, it is concluded that in the case of the benzene cyanomethylation the Pd nanoparticles play the dual roles, as the catalyst to catalyse the substitution reaction of benzene with the cyanomethyl radical, and as the electron receiver to reduce the recombination of the photoexcited electron and hole in the $\mathrm{TiO}_{2}$ photocatalyst, although they could not contribute as a catalyst to the cyanomethylation of aliphatic hydrocarbons.

\section{Introduction}

Cyanomethylation is one of the useful synthesis methods to provide intermediates of medicines, polymers, and so on. In order to obtain cyanomethylated compounds with high yield, functionalized nitriles such as trimethylsilyl acetonitrile, ${ }^{1}$ cyanoacetate salts ${ }^{2}$ and chloroacetonitrile ${ }^{3}$ are typical reagents, and it is recognised that acetonitrile is not a useful nitrile source due to the very week acidity. Thus the direct cyanomethylation with acetonitrile has examined by using some kinds of base reagents such as $\mathrm{NaH}^{5}{ }^{5}$ cesium pivalate ${ }^{6}$ and $\mathrm{NaOH}^{7}$ to induce $\mathrm{C}-\mathrm{H}$ bond dissociation of acetonitrile. However, available strong base reactants are limited because they tend to promote side reactions.

On the other hand, radical initiators ${ }^{8}$ and metal complex catalysts ${ }^{4,9}$ have been developed for the direct $\mathrm{C}-\mathrm{H}$ bond activation of acetonitrile as base-free cyanomethylation. For example, J. Li et al. reported that di-tert-butyl peroxide (DTBP) can activate acetonitrile

Graduate School of Human and Environmental Studies, Kyoto University, Yoshida Nihonmatsu-cho, Sakyo-ku, Kyoto 606-8501 Japan

E-mail: yoshida.hisao.2a@kyoto-u.ac.jp

b. Research Fellow of the Japan Society for the Promotion of Science

Department of Applied Chemistry, Graduate School of Engineering, Nagoya University, Furo-cho, Chikusa-ku, Nagoya, 464-8603, Japan.

d. Institute for Liberal Arts and Science, Kyoto University, Yoshida Nihonmatsu-cho, Sakyo-ku, Kyoto, 606-8501, Japan

e. Elemental Strategy Initiative for Catalysts and Batteries (ESICB), Kyoto University, Kyotodaigaku-katsura, Nishikyo-ku, Kyoto, 615-8520, Japan Electronic Supplementary Information (ESI) available: See DOI: $10.1039 / \times 0 \times x 00000 x$ to form cyanomethyl radical for the cyanomethylation of aliphatic amides. ${ }^{8 c}$ Chakraborty et al. developed the cyanomethylation of aldehydes with $\mathrm{Ni}$ complex catalyst promoting the $\mathrm{C}-\mathrm{H}$ cleavage of acetonitrile at room temperature. ${ }^{4}$ In view of the sustainable chemistry, catalytic process is more desirable. However, in heterogeneous catalytic reaction systems, it has always been pointed out that the products separation from the reaction mixture is not easy. Thus, heterogeneous catalysts have been desired for the direct cyanomethylation with acetonitrile, but it still has not been achieved except for our previous study. ${ }^{10}$

In our laboratory, several photocatalytic reaction systems for direct functionalization of alkene ${ }^{11}$ and aromatic compounds ${ }^{12,13}$ have been investigated by using metal loaded $\mathrm{TiO}_{2}$ photocatalysts $\left(\mathrm{M} / \mathrm{TiO}_{2}, \mathrm{M}=\mathrm{Pt}\right.$ or $\left.\mathrm{Pd}\right)$. The $\mathrm{Pt} / \mathrm{TiO}_{2}$ photocatalyst promotes functionalization of benzene with water ${ }^{12}$ and ammonia ${ }^{13}$ to yield phenol and aniline, respectively. On one hand, the $\mathrm{Pd} / \mathrm{TiO}_{2}$ photocatalyst promotes the direct cyanomethylation of various aromatic compounds with acetonitrile to yield banzyl cyanides. ${ }^{10}$ The $\mathrm{Pd} / \mathrm{TiO}_{2}$ photocatalyst also forward reactions between benzene and ethers to form phenylated ethers..$^{14}$ In general, Pt nanoparticles on a semiconductor photocatalyst can much improve the photocatalytic activity compared to other metals such as Pd. It is considered that Pt nanoparticles function as a charge separator for the photoexcited electron and hole because of the large work function of Pt. ${ }^{15}$ However, it is noted that the direct cyanomethylation of benzene hardly proceeds over the $\mathrm{Pt} / \mathrm{TiO}_{2}$ photocatalyst, while it is well promoted over the $\mathrm{Pd} / \mathrm{TiO}_{2}$ photocatalyst only under photoirradiation. ${ }^{10}$ This shows that the $\mathrm{Pd}$ nanoparticles on the $\mathrm{TiO}_{2}$ photocatalyst itself played another role in addition to the well-known function as an electron receiver from the $\mathrm{TiO}_{2}$ photocatalyst, suggesting that the $\mathrm{Pd}$ nanoparticles would contribute as a metal 
catalyst to this reaction in the presence of photocatalyst. ${ }^{10}$ In literature, some articles have described the function of the metal particles as a catalyst coupled with the photocatalysis. ${ }^{10,14,16}$

In the present study, the photocatalytic cyanomethylation of cyclohexane and cyclohexene were examined by using the $\mathrm{M} / \mathrm{TiO}_{2}$ photocatalysts and their reaction mechanisms were discussed. In addition, in order to clarify the function of the metal nanoparticles in $\mathrm{TiO}_{2}$ photocatalyst, the physical mixture of the $\mathrm{TiO}_{2}$ photocatalyst and a supported Pd or Pt metal catalyst was applied for the cyanomethylations of cyclohexane, cyclohexene, and benzene.

\section{Results and discussion}

\subsection{Cyanomethylation of cyclohexane}

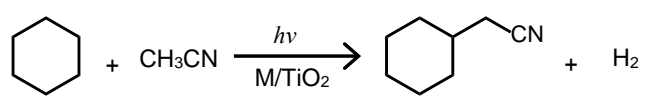

Table 1 shows the result of the reaction between cyclohexane and acetonitrile (eq. 1) over the photocatalyst samples. The $\mathrm{Pt} / \mathrm{TiO}_{2}$ sample gave cyanomethyl cyclohexane (CC) as the desired product, the amount of which was lower than that of succinonitrile (SN) as a major by-product (Table 1, entry 1). A small amount of bicyclohexyl (BC), cyclohexyl methyl ketone (CMK) and cyclohexanone were also detected because of the coexistence of water in the reaction mixture. Hydrogen was detected as a gaseous product although the accuracy for quantitative determination might be low. The reaction over the $\mathrm{Pd} / \mathrm{TiO}_{2}$ sample gave the same products (Table1, entry 2 ), but the yields of these products were much less than those over the $\mathrm{Pt} / \mathrm{TiO}_{2}$ sample, indicating that the $\mathrm{Pt}$ nanoparticles on the $\mathrm{TiO}_{2}$ photocatalyst can enhance the charge separation of excited electrons and holes more efficiently and thus gave more products. ${ }^{14}$ In both cases, the selectivity for this cyanomethylation was not high compared with the cyanomethylation of benzene in the previous study. ${ }^{12}$ The pristine $\mathrm{TiO}_{2}$ photocatalyst exhibited much less activity than metal loaded ones (Table 1, entry 3 ), showing that these metal nanoparticles could act as a cocatalyst enhancing the electron-hole separation.

The effect of the addition of the $\mathrm{M} / \mathrm{Al}_{2} \mathrm{O}_{3}$ sample to the $\mathrm{Pt} / \mathrm{TiO}{ }_{2}$ photocatalyst was also examined in this reaction system for the discussion mentioned later to know the catalytic effect of the loaded metals. According to the literature, ${ }^{17}$ in the presence of platinum black, the catalytic activity of $\mathrm{TiO}_{2}$ photocatalyst is much improved because physical contact of $\mathrm{Pt}$ particles with $\mathrm{TiO}_{2}$ photocatalyst enhances the charge transfer of photogenerated electron from the $\mathrm{TiO}_{2}$ photocatalyst to decrease the recombination of electron-hole pairs. To investigate the catalytic function of the metal nanoparticles, the direct physical contract of metal nanoparticles and $\mathrm{TiO}_{2}$ photocatalyst should be avoided. Thus, the $\mathrm{M} / \mathrm{Al}_{2} \mathrm{O}_{3}$ sample were employed here. Since in these supported samples the metal nanoparticles were dispersed and stabilized on the surface of the $\mathrm{Al}_{2} \mathrm{O}_{3}$ with large surface area and porous structure, the nanoparticles could not contact with the $\mathrm{TiO}_{2}$ surface so easily, allowing us to ignore the effect of the metal nanoparticles as the electron receiver from the $\mathrm{TiO}_{2}$ photoctalyst. As listed in Table 1 entries 4-6, the yield of $\mathrm{CC}$ decreased in the coexistence of the $\mathrm{Pd} / \mathrm{Al}_{2} \mathrm{O}_{3}$ sample, the $\mathrm{Pt} / \mathrm{Al}_{2} \mathrm{O}_{3}$ sample, and the bare $\mathrm{Al}_{2} \mathrm{O}_{3}$ sample. These results indicated that the contribution of the catalysis by the supported $\mathrm{Pd}$ and $\mathrm{Pt}$ metal particles was not so large or negligible in this reaction system. The presence of these additional powders reduced the product yields, which would originate from the shading the photocatalyst, adsorbing some species, and so on.

Table 1 Results of the photocatalytic reaction tests for the cyanomethylation of cyclohexane with acetonitrile over the photocatalyst samples and some mixtures ${ }^{a}$

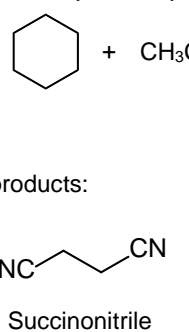

(SN)
(BC)

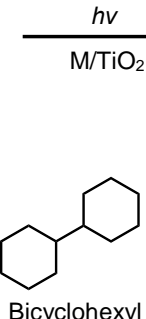

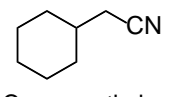

Cyanomethyl cyclohexane (CC)

\begin{tabular}{|c|c|c|c|c|c|c|c|}
\hline & $\begin{array}{l}\text { Succinonitrile } \\
\text { (SN) }\end{array}$ & $\begin{array}{r}\text { Bicyclo } \\
\text { (BC }\end{array}$ & & $\begin{array}{l}\text { clohexe } \\
\text { thyl ke } \\
\text { (CMK }\end{array}$ & & $\begin{array}{r}\text { Cyclohe } \\
(1\end{array}$ & none \\
\hline \multirow[t]{2}{*}{ Entry } & \multirow[t]{2}{*}{ Catalyst $^{b}$} & \multicolumn{6}{|c|}{ Products $/ \mu \mathrm{mol}$} \\
\hline & & $\mathrm{CC}$ & $\mathrm{SN}$ & $\mathrm{BC}$ & CMK & 1 & $\mathrm{H}_{2}$ \\
\hline 1 & $\mathrm{Pt} / \mathrm{TiO}_{2}$ & 10 & 16 & 2.0 & 1.5 & 1.1 & 70 \\
\hline 2 & $\mathrm{Pd} / \mathrm{TiO}_{2}$ & 2.6 & 2.5 & 0.13 & 0.36 & 0.4 & 15 \\
\hline 3 & $\mathrm{TiO}_{2}$ & n.d.c & $\operatorname{tr}^{d}$ & n.d. & 0.27 & tr. & $\operatorname{tr}$ \\
\hline 4 & $\begin{array}{l}\mathrm{Pt} / \mathrm{TiO}_{2}+ \\
\mathrm{Pd}(1.0) / \mathrm{Al}_{2} \mathrm{O}_{3}{ }^{e}\end{array}$ & 4.2 & 4.0 & 0.58 & 0.87 & tr. & 28 \\
\hline 5 & $\begin{array}{l}\mathrm{Pt} / \mathrm{TiO}_{2}+ \\
\mathrm{Pt}(1.0) / \mathrm{Al}_{2} \mathrm{O}_{3} e\end{array}$ & 4.3 & 4.8 & 0.72 & 0.25 & tr. & 28 \\
\hline 6 & $\begin{array}{l}\mathrm{Pt} / \mathrm{TiO}_{2}+ \\
\mathrm{Al}_{2} \mathrm{O}_{3} e^{2}\end{array}$ & 4.0 & 7.5 & 1.7 & 0.56 & tr. & 34 \\
\hline
\end{tabular}

a Reaction condition: The $\mathrm{M}(0.1 \mathrm{wt} \%) / \mathrm{TiO}_{2}$ photocatalyst $0.20 \mathrm{~g}$, cyclohexane $0.93 \mathrm{mmol}(0.10 \mathrm{~mL})$, acetonitrile $72 \mathrm{mmol}(3.8 \mathrm{~mL})$, and water $5.6 \mathrm{mmol}(0.10 \mathrm{~mL})$. Reaction time was $1 \mathrm{~h}$. Reaction temperature was ca. $310 \mathrm{~K}$. The wavelength of the irradiation light was $365 \pm 20 \mathrm{~nm}$ and the light intensity was $27 \mathrm{~mW} \mathrm{~cm}^{-2}$ measured at $360 \pm 15 \mathrm{~nm}$. ${ }^{b}$ The loading amount of metal on the $\mathrm{TiO}_{2}$ sample was $0.1 \mathrm{wt} \%$, and the loading amount of metals on the $\mathrm{Al}_{2} \mathrm{O}_{3}$ support was $1.0 \mathrm{wt} \% .^{c}$ not detected. ${ }^{d}$ trace. ${ }^{e} \mathrm{~A}$ mixture of the $\mathrm{M}(0.1 \mathrm{wt} \%) / \mathrm{TiO}_{2}$ photocatalyst of $0.20 \mathrm{~g}$ and the $\mathrm{M}(1.0 \mathrm{wt} \%) / \mathrm{Al}_{2} \mathrm{O}_{3}$ sample or the bare $\mathrm{Al}_{2} \mathrm{O}_{3}$ sample of $0.20 \mathrm{~g}$ was used.

Since SN and BC were given by each photocatalyst, both acetonitrile and cyclohexane molecule would be oxidized to by the $\mathrm{TiO}_{2}$ photocatalysts to form each radical species, followed by the radical homo-coupling reaction between them. As shown in our previous study, ${ }^{10}$ acetonitrile can be oxidized to a cyanomethyl radical by a $\mathrm{Pd} / \mathrm{TiO}_{2}$ photocatalyst under the light. In the present study, ESR measurement was carried out in order to confirm the formation of radical species from cyclohexane in the presence of the photocatalyst. Fig. 1 shows the ESR spectra of cyclohexane solution containing PBN as a spin trap reagent in some conditions. While no signals except for those of $\mathrm{Mn}^{2+}$ marker was observed without the photocatalyst (Fig. 1a) or light (Fig. 1b), new triplet signals were detected in the presence of the $\mathrm{Pd} / \mathrm{TiO}_{2}$ photocatalyst upon light irradiation (Fig. 1C). Although the hyperfine structure was not clearly observed due to the week signals, these signals would be a radical species generated by the photocatalyst. Judging from the compounds in the cell under this condition, it can be considered that the triplet signals could originate from the nitrogen of the PBN adduct shown in Fig. 1 with the $g$ value $=2.006$ and $A^{N}=1.32 \mathrm{mT}, 18$ indicating that the cyclohexene-PBN adduct would be detected. Signals assignable to the hydrogen radical adduct could not be observed in this condition. 

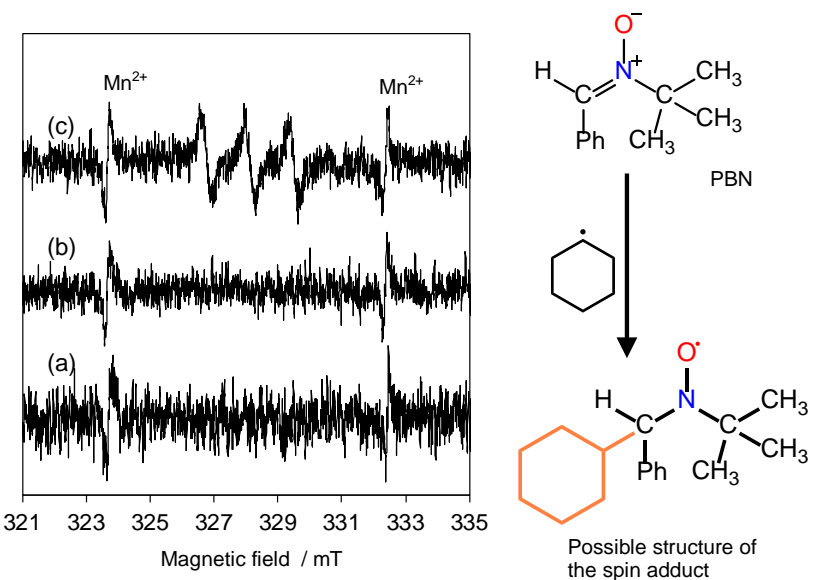

Fig. 1 ESR spectra of the cyclohexane solution containing a spin trap reagent ( $\mathrm{PBN}$ ) measured (a) after light irradiation for $120 \mathrm{~min}$ without the $\mathrm{Pd} / \mathrm{TiO}_{2}$ sample, (b) in the presence of the $\mathrm{Pd} / \mathrm{TiO}_{2}$ sample in the dark, and (c) after light irradiation for $120 \mathrm{~min}$ in the presence of the $\mathrm{Pd} / \mathrm{TiO}_{2}$ sample.

To discuss the reaction mechanism, some reaction tests were carried out with deuterated reagents over the $\mathrm{M} / \mathrm{TiO}_{2}$ samples. When deuterated acetonitrile $\left(\mathrm{CD}_{3} \mathrm{CN}\right)$ was reacted with cyclohexane $\left(\mathrm{C}_{6} \mathrm{H}_{12}\right)$ over the $\mathrm{Pt} / \mathrm{TiO}_{2}$ sample (Table 2 , entry 2 ), the yield of $\mathrm{CC}$ was almost similar to, or slightly larger than, the result using normal reagents $\left(\mathrm{C}_{6} \mathrm{H}_{12}\right.$ and $\mathrm{CH}_{3} \mathrm{CN}$, Table 2 , entry 1$)$, i.e. the $\mathrm{k}_{H} / \mathrm{k}_{D}$ value for the $\mathrm{CC}$ formation was not larger than unity. On the other hand, when deuterated cyclohexane $\left(C_{6} D_{12}\right)$ was used for the reaction, the yield of CC clearly decreased, i.e., the $\mathrm{k}_{H} / \mathrm{k}_{\mathrm{D}}$ value for the CC formation was 1.9 (Table 2, entry 3). This kinetic isotopic effect (KIE) clearly evidenced that the $\mathrm{C}-\mathrm{H}$ bond activation of cyclohexane would be the rate-determining step (RDS) to give CC in this condition. The similar $\mathrm{KIE}$ was observed for the reaction over the $\mathrm{Pd} / \mathrm{TiO}_{2}$ sample (Table 2, entries 4-6), showing that the RDS would be the same step as the case of the $\mathrm{Pt} / \mathrm{TiO}_{2}$ sample. These results were consistent with the order of the $\mathrm{C}-\mathrm{H}$ bond dissociation energy ${ }^{19 a}$ (Table $\mathrm{S} 1$ ): cyclohexane $\left(416 \mathrm{KJ} \mathrm{mol}^{-1}\right)>$ acetonitrile $\left(406 \mathrm{KJ} \mathrm{mol}^{-1}\right.$ ), where the RDS corresponded to the cleavage of the stronger bond.

Table 2 Results of the reaction tests with isotopic compounds for the direct cyanomethylation of cyclohexane by the $\mathrm{M}(0.1$ wt $\%) / \mathrm{TiO}_{2}$ photocatalysts ${ }^{a}$

\begin{tabular}{|c|c|c|c|c|c|c|c|c|}
\hline \multirow[t]{2}{*}{ Entry } & \multirow{2}{*}{$\begin{array}{l}\text { Catalys } \\
\mathrm{t}\end{array}$} & \multirow{2}{*}{$\begin{array}{l}\text { Isotopic } \\
\text { compound }\end{array}$} & \multicolumn{3}{|c|}{ Products $^{b} / \mu \mathrm{mol}$} & \multicolumn{3}{|c|}{$\mathrm{k}_{\mathrm{H}} / \mathrm{k}_{\mathrm{D}}^{c}$} \\
\hline & & & CC & SN & $B C$ & CC & SN & $\mathrm{BC}$ \\
\hline 1 & & none & 10 & 16 & 2.0 & - & - & - \\
\hline 2 & $\mathrm{Pt} / \mathrm{TiO}_{2}$ & $\mathrm{CD}_{3} \mathrm{CN}$ & 12 & 3.0 & 19 & 0.83 & 5.3 & 0.11 \\
\hline 3 & & $\mathrm{C}_{6} \mathrm{D}_{12}$ & 5.2 & 19 & 0.90 & 1.9 & 0.84 & 2.2 \\
\hline 4 & & none & 2.0 & 2.5 & 0.29 & - & - & - \\
\hline 5 & $\mathrm{Pd} / \mathrm{TiO}_{2}$ & $\mathrm{CD}_{3} \mathrm{CN}$ & 2.6 & n.d. ${ }^{d}$ & 2.1 & 0.77 & - & 0.14 \\
\hline 6 & & $\mathrm{C}_{6} \mathrm{D}_{12}$ & 1.7 & 2.6 & 0.11 & 1.2 & 0.96 & 2.6 \\
\hline
\end{tabular}

${ }^{a}$ The reaction condition was the same as that described in the caption of in Table $1 .{ }^{b} \mathrm{CC}=$ cyanomethyl cyclohexane, $\mathrm{SN}=$ succinonitrile, $\mathrm{BC}=$ bicyclohexyl. ${ }^{c} \mathrm{k}_{\mathrm{H}} / \mathrm{k}_{\mathrm{D}}(\mathrm{CC})=$ (yield of $\mathrm{CC}$ with the normal reagent) / (yield of $C C$ with the deuterated reagent). The values of $k_{H} / k_{D}(S N)$ and $k_{H} / k_{D}(B C)$ were calculated in the similar ways. ${ }^{d}$ Not detected.

On the other hand, it should be considered that the $\mathrm{k}_{\mathrm{H}} / \mathrm{k}_{\mathrm{D}}$ values less than unity (inverse KIE) can provide more important information of the reaction mechanism. When the reaction between $\mathrm{C}_{6} \mathrm{H}_{12}$ and $\mathrm{CD}_{3} \mathrm{CN}$ was carried out, the $\mathrm{k}_{\mathrm{H}} / \mathrm{k}_{\mathrm{D}}$ values for the yields of $\mathrm{CC}$ and $\mathrm{BC}$ were 0.83 and 0.11 , respectively over the $\mathrm{Pt} / \mathrm{TiO}_{2}$ sample (Table 2 , entry 2) and 0.77 and 0.14 , respectively over the $\mathrm{Pd} / \mathrm{TiO}_{2}$ sample (Table 2, entry 5), which can be recognised as the inverse KIE. In this reaction, both cyclohexane and acetonitrile would be oxidized by the photocatalytically-generated hole to become corresponding radical species, i.e., the two reactions for the radical formation competitively take place to consume the limited number of the photogenerated holes. The use of $\mathrm{CD}_{3} \mathrm{CN}$ instead of $\mathrm{CH}_{3} \mathrm{CN}$ would decrease the oxidation rate of acetonitrile due to the high C-D bond dissociation energy, which enhanced the oxidation of competitor instead, i.e., the oxidation rate of $\mathrm{C}_{6} \mathrm{H}_{12}$ to form the cyclohexyl radical. Since the RDS in these coupling reactions was the formation of cyclohexyl radical, both formation rates of $\mathrm{CC}$ and $\mathrm{BC}$ increased in the presence of $\mathrm{CD}_{3} \mathrm{CN}$ as a result. In the reaction between $\mathrm{CH}_{3} \mathrm{CN}$ and $\mathrm{C}_{6} \mathrm{D}_{12}$, since the $\mathrm{C}-\mathrm{D}$ bond dissociation of $\mathrm{C}_{6} \mathrm{D}_{12}$ was more difficult, the competitive oxidation was enhanced, resulting that the concentration of cyanomethyl radical increased. In consequence, the yield of $\mathrm{SN}$ increased and the $\mathrm{k}_{\mathrm{H}} / \mathrm{k}_{\mathrm{D}}$ values for $\mathrm{SN}$ production were lower than unity such as 0.84 nad 0.94 (Table 2, entries 3 and 6). These results clarified that the competitive hole oxidation of both cyclohexane and acetonitrile took place to form their radical species.

Considering the results of the ESR measurements and the kinetic isotopic effect, the reaction mechanism for the cyanomethylation of cyclohexane should be radical cross-coupling, which would be a two photon process, as shown in Fig. 2. First, photoexited electrons and holes generate on $\mathrm{TiO}_{2}$ photocatalyst under photoirradiation. The holes on the $\mathrm{TiO}_{2}$ surface oxidize both reactants, cyclohexane and acetonitrile, to form the corresponding radical species and protons, which proceeds competitively. Then, CC can be produced through the cross-coupling reaction between the cyclohexyl radical and the cyanomethyl radical, while BC and SN can be also formed via each homo-coupling reaction similarly. Produced protons are reduced by the photoexcited electrons to hydrogen radicals, followed by their radical coupling to form molecular hydrogen. These reactions can be promoted by the Pt or $\mathrm{Pd}$ loaded $\mathrm{TiO}_{2}$, although the former exhibits higher activity than the latter. In the cyanomethylation of cyclohexane proceeding via radical cross-coupling, the loaded metal would function as the electron receiver to reduce the recombination of the photoexcited electron and hole in the $\mathrm{TiO}_{2}$ photocatalyst.

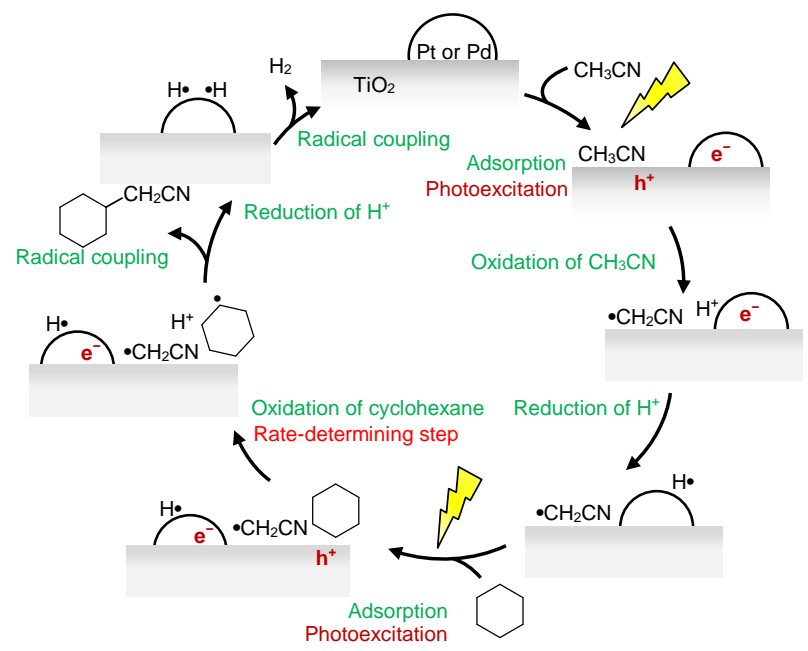

Fig. 2 Proposed reaction mechanism of the direct cyanomethylation between cyclohexane and acetonitrile over the $\mathrm{M} / \mathrm{TiO}_{2}$ photocatalyst. 
It was also confirmed that the cyanomethylation of $n$-hexane was also promoted by both the $\mathrm{Pt} / \mathrm{TiO}_{2}$ photocatalyst and the $\mathrm{Pd} / \mathrm{TiO}_{2}$ photocatalyst (Table S2), where the former was more active than the latter similar to the case of cyclohexane.

\subsection{Cyanomethylation of cyclohexene}

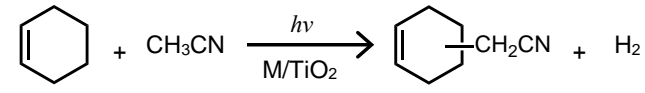

The direct cyanomethylation of cyclohexene with acetonitrile (eq. 2) was examined to know the property of the photocatalytic cyanomethylation system and to expand the application to unsaturated hydrocarbon. Table 3 shows the results of the reaction tests with the $\mathrm{M} / \mathrm{TiO}_{2}$ samples. The main product was assigned to $2-$ cyclohexenyl acetonitrile (CA) according to the following results; (i) the retention time of the main product in the gas chromatograph was close to but clearly different from that of a purchased reagent of 1cyclohexenyl acetonitrile, (ii) the mass fragments in the mass spectrum of the main product were almost the same but not identical to those of the purchased reagent of 1-cyclohexenyl acetonitrile (Fig. S3), and (iii) it is fact that the $\mathrm{C}-\mathrm{H}$ bond dissociation energy at allylic position is the lowest in a cyclohexene molecule ${ }^{19 b}$ (Table S1). Each photocatalyst produced CA, a desired cyanomethylated cyclohexene, as the major product over. The $\mathrm{Pt} / \mathrm{TiO}_{2}$ sample produced higher amount of CA than the $\mathrm{Pd} / \mathrm{TiO}_{2}$ sample (Table 3, entries 1 and 2). Since the pristine $\mathrm{TiO}_{2}$ sample exhibited very small activity, the metal nanoparticles were confirmed to function as the electron receiver enhancing the electron-hole separation (Table 3, entry 3 ). The physical mixture of the $\mathrm{Pt} / \mathrm{TiO}_{2}$ sample and the $\mathrm{Pd} / \mathrm{Al}_{2} \mathrm{O}_{3}$ sample did not exhibit higher yield of $\mathrm{CA}$ than the $\mathrm{Pt} / \mathrm{TiO}_{2}$ sample alone (Table 3, entry 4). The byproducts were cyanomethyl cyclohexane (CC), some kinds of homo-coupling products from cyclohexene, e.g., bicyclohexenyls (bc) such as $\left[1,1^{\prime}\right.$ bi(cyclohexane)]-2,2'-diene, and the hydrated compounds such as cyclohexylcyclohexene. The small amounts of cyclohexenol and cyclohexenone were also detected because of the presence of water. Interestingly, SN was not detected even though large amount of acetonitrile exited in the reactor, which would originate from the much lower $\mathrm{C}-\mathrm{H}$ bond dissociation energy of the allylic position of cyclohexenethe $\mathrm{C}-\mathrm{H}$ bond of cyclohexene $\left(350 \mathrm{~kJ} \mathrm{~mol}^{-1}\right)^{17 \mathrm{~b}}$ than that of acetonitrile (406 kJ mol-1) $)^{17 a}$ (Table S1).

To discuss the reaction mechanism, the reaction tests with the isotopic compounds was carried out over the $\mathrm{Pd} / \mathrm{TiO}_{2}$ photocatalyst. As shown in Table 4, the $k_{H} / k_{D}$ value for the CA formation was 3.9 when deuterated acetonitrile $\left(\mathrm{CD}_{3} \mathrm{CN}\right)$ was used. This suggests that the $\mathrm{C}-\mathrm{H}$ bond activation of acetonitrile would be the ratedetermining step in this condition, which is clearly different from the case of the cyanomethylation of cyclohexane mentioned above. The RDS in these reactions seems related to the order of the $\mathrm{C}-\mathrm{H}$ bond dissociation energy of the reactants $\mathrm{s}^{19 \mathrm{~b}}$ (Table S1), cyclohexane (416 $\left.\mathrm{kJ} \mathrm{mol}^{-1}\right)>$ acetonitrile $\left(406 \mathrm{~kJ} \mathrm{~mol}^{-1}\right)>$ cyclohexene $\left(350 \mathrm{~kJ} \mathrm{~mol}^{-1}\right.$ at allylic position as the lowest one), i.e., the RDS would be determined by the difficulty of the radical formation through the $\mathrm{C}-\mathrm{H}$ bond dissociation. Thus, the RDS in the cyanomethylation of cyclohexane was the formation of the cyclohexane radical, while that in the cyanomethylation of cyclohexene was the formation of cyanomethyl radical. The $k_{H} / k_{D}$ value for the yield of bc was less than unity in the reaction between cyclohexene and $\mathrm{CD}_{3} \mathrm{CN}$, indicating that the oxidative reactions of cyclohexene and acetonitrile to form the corresponding radical species competitively proceed in the similar way as discussed above.

Table 3 Results of the photocatalytic reaction tests for the cyanomethylation of cyclohexene with acetonitrile over the $\mathrm{M} / \mathrm{TiO}_{2}$ photocatalyst samples or a mixture of the $\mathrm{Pt} / \mathrm{TiO}_{2}$ and $\mathrm{Pt} / \mathrm{Al}_{2} \mathrm{O}_{3}$ samples. ${ }^{a}$

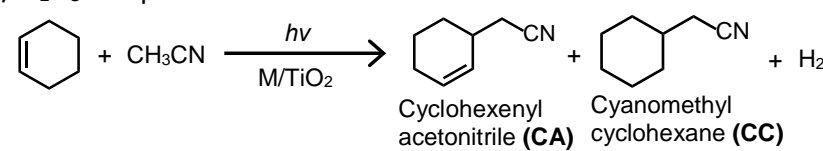

Byproducts:

$$
\text { Succinonitrile }
$$
(SN)

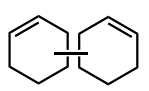

Bicyclohexenyl

(bc)

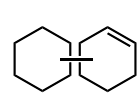

Cyclohexenylcyclohexene

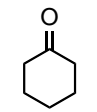

Cyclohexenone (2)

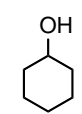

Cyclohexenol (3)

\begin{tabular}{lllllccccc}
\hline Entry & Catalyst $^{b}$ & \multicolumn{8}{c}{ Products $/ \mu \mathrm{mol}$} \\
\cline { 3 - 10 } & & $\mathrm{CA}$ & $\mathrm{CC}$ & $\mathrm{SN}$ & $\mathrm{Bc}$ & 1 & $\mathrm{H}_{2}$ & 2 & 3 \\
\hline 1 & $\mathrm{Pt} / \mathrm{TiO}_{2}$ & 42 & 5.4 & tr. $^{c}$ & 24 & n.d. & 90 & 1.4 & 0.81 \\
2 & $\mathrm{Pd} / \mathrm{TiO}_{2}$ & 16 & 7.8 & n.d. $^{d}$ & 8.4 & 6.6 & 10 & 2.0 & 1.9 \\
3 & $\mathrm{TiO}_{2}$ & n.d. & n.d. & n.d. & 2.4 & n.d. & 1.7 & 1.1 & 0.24 \\
4 & $\mathrm{Pt} / \mathrm{TiO}_{2}+$ & 30 & 4.1 & n.d. & 22 & n.d. & 70 & 1.0 & 0.52
\end{tabular}

${ }^{a}$ Reaction condition: Catalyst $0.20 \mathrm{~g}$, cyclohexene $0.98 \mathrm{mmol}(0.10$ $\mathrm{mL}$ ), acetonitrile $72 \mathrm{mmol}(3.8 \mathrm{~mL})$, and water $5.6 \mathrm{mmol}(0.10 \mathrm{~mL})$. Other conditions were the same as those described in the caption of Table 1. ${ }^{b}$ The loading amount of metal on the $\mathrm{TiO}_{2}$ sample was $0.1 \mathrm{wt} \%$, and the loading amount of metals on the $\mathrm{Al}_{2} \mathrm{O}_{3}$ support was $1.0 \mathrm{wt} \%$. $^{c}$ trace. ${ }^{d}$ Not detected. e A mixture of the $\mathrm{M}(0.1 \mathrm{wt} \%) / \mathrm{TiO}_{2}$ photocatalyst of $0.20 \mathrm{~g}$ and the $\mathrm{M}(1.0 \mathrm{wt} \%) / \mathrm{Al}_{2} \mathrm{O}_{3}$ sample or the bare $\mathrm{Al}_{2} \mathrm{O}_{3}$ sample of $0.20 \mathrm{~g}$ was used.

Table 4 Results of the reaction tests with isotopic compounds for the cyanomethylation of cyclohexene over the $\mathrm{Pd} / \mathrm{TiO}_{2}$ sample. ${ }^{a}$

\begin{tabular}{ccccccl}
\hline \multirow{2}{*}{ Entry } & $\begin{array}{l}\text { Isotopic } \\
\text { compound }\end{array}$ & \multicolumn{3}{c}{ Products $^{b} / \mu \mathrm{mol}$} & \multicolumn{2}{c}{$\mathrm{k}_{\mathrm{H}} / \mathrm{k}_{\mathrm{D}}{ }^{c}$} \\
\cline { 3 - 7 } & $\mathrm{CA}$ & $\mathrm{BC}$ & $\mathrm{SN}$ & $\mathrm{CA}$ & $\mathrm{bc}$ \\
\hline 1 & None & 12 & 9.1 & n.d ${ }^{d}$ & - & - \\
2 & $\mathrm{CD}_{3} \mathrm{CN}$ & 3.1 & 18 & n.d. & 3.9 & 0.48 \\
3 & $\mathrm{C}_{6} \mathrm{D}_{10}$ & 12 & 2.0 & n.d. & 1.0 & 5.4
\end{tabular}

a Reaction condition: A Pyrex test tube (ca. $70 \mathrm{~mL}$ ) was used as a reactor. Other conditions were the same as those described in the caption of Table 1. ${ }^{b} \mathrm{CA}=2$-cyclohexenyl acetonitrile, $\mathrm{bc}=$ the sum of bicyclohexenyl including isomers, $\mathrm{SN}=$ succinonitrile. $^{c}$ $\mathrm{k}_{\mathrm{H}} / \mathrm{k}_{\mathrm{D}}=$ (yield with the normal compound) / (yield with the deuterated reagent). ${ }^{d}$ Not detected.

The radical formation from cyclohexene over the $\mathrm{Pd} / \mathrm{TiO}$ sample was confirmed by ESR measurements. As shown in Fig. 4, the sharp signals were detected in the presence of the $\mathrm{Pd} / \mathrm{TiO}_{2}$ sample under photoirradiation, which means radical species can be generated from cyclohexene by the photocatalyst. The signals showed a double triplet with the $g$ value of 2.006 and the hyperfine coupling constant of $A^{\mathrm{N}}=1.32 \mathrm{mT}$ (triplet) and $A^{\mathrm{H}}=0.21 \mathrm{mT}$ (doublet), respectively. The possible spin adduct structure was suggested to be the cyclohexenePBN adduct shown in Fig. 3, indicating that the cyclohexenyl radical was formed from cyclohexene. The signal intensity of this spin adduct with cyclohexene was much larger than that of the spin adduct with cyclohexane, consisting with the radical formation rate expected from the $\mathrm{C}-\mathrm{H}$ bond dissociation energy ${ }^{19 \mathrm{~b}}$ of the cyclohexane (416 kJ $\mathrm{mol}^{-1}$ ) and cyclohexene (350 kJ mol${ }^{-1}$ at allylic position). Signals 
originating from the hydrogen radical adduct could not be observed in this condition. Since the radical formation of the cyanomethyl radical was confirmed with the $\mathrm{Pd} / \mathrm{TiO}_{2}$ photocatalyst in the previous study, ${ }^{10}$ it is proposed that the reaction between cyclohexene and acetonitrile is a radical cross-coupling between cyclohexenyl radical and cyanomethyl radical.

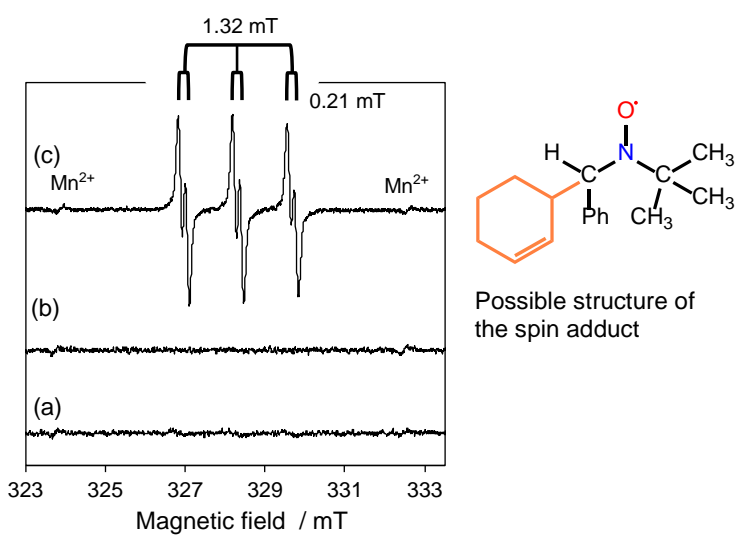

Fig. 3 ESR spectra of the cyclohexene solution containing PBN in argon atmosphere, (a) measured after light irradiation for $20 \mathrm{~min}$ without the $\mathrm{Pd} / \mathrm{TiO}_{2}$ sample, (b) measured in the presence of the $\mathrm{Pd} / \mathrm{TiO}_{2}$ sample without light irradiation, (c) measured after light irradiated for $10 \mathrm{~min}$ in the presence of the $\mathrm{Pd} / \mathrm{TiO}_{2}$ sample.

Considering from the KIE and the ESR signals, the reaction between cyclohexene and acetonitrile can be explained by the radical coupling mechanism involving two photoexcitation steps as shown in Fig. 4. The photoformed hole oxidizes cyclohexene to cyclohexenyl radical, in which the radical centre is at the allylic position. The photoformed hole oxidizes also acetonitrile to cyanomethyl radical, which is the rate determining step (RDS) in this condition. Then, the cross-coupling proceeds between these radicals, while homo-coupling reactions also undergo as the side reactions. In the current reaction condition, since the cyclohexenyl radical would be predominantly formed compared with the cyanomethyl radical, $\mathrm{CA}$ and bc were produced as the major products, but SN was rarely formed.

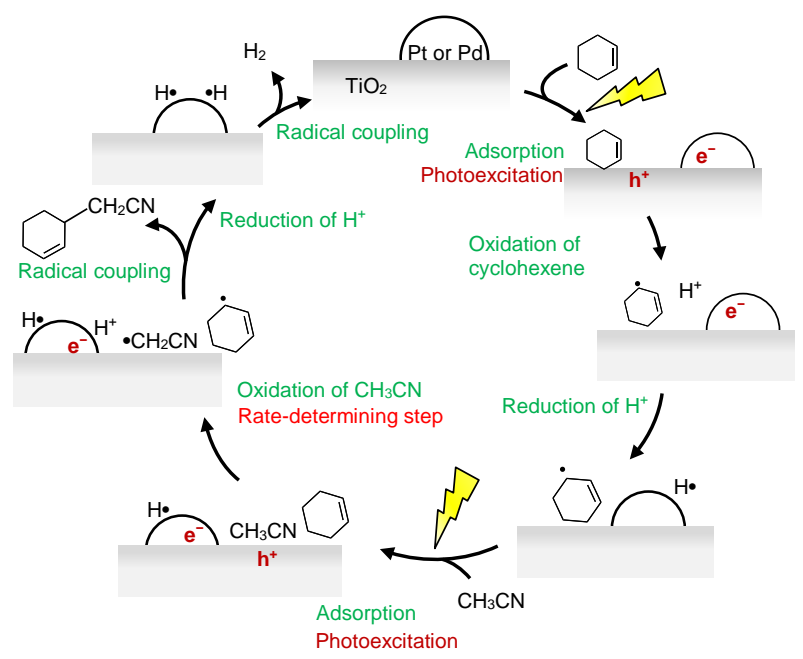

Fig. 4 Proposed reaction mechanism of the direct cyanomethylation between cyclohexene and acetonitrile over the $\mathrm{M} / \mathrm{TiO}_{2}$ photocatalyst.

\subsection{Cyanomethylation of benzene}

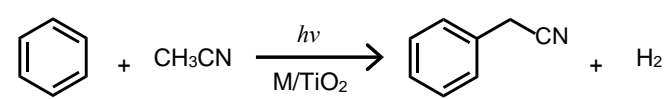

In the previous study, we found that the cyanomethylation of benzene (eq. 3) can be promoted by the hybrid $\mathrm{Pd} / \mathrm{TiO}_{2}$ catalyst consisting of $\mathrm{Pd}$ thermal catalyst and $\mathrm{TiO}_{2}$ photocatalyst. ${ }^{10} \mathrm{Here}$, it was again confirmed that the reaction between benzene and acetonitrile over the $\mathrm{Pd} / \mathrm{TiO}_{2}$ sample gave benzyl cyanide $(\mathrm{BnCN})$ as the major product, and phenol $(\mathrm{PhOH})$ and succinonitrile $(\mathrm{SN})$ as the minor products (Table 5, entry 2). The formation of SN suggested that cyanomethyl radical would be actually generated through the photocatalytic oxidation of acetonitrile before the homo-coupling. In fact, ESR measurement elucidated the formation of the cyanomethyl radical in the presence of the $\mathrm{Pd} / \mathrm{TiO}_{2}$ sample under photoirradiation. ${ }^{10}$ Since the biphenyl was not detected as a homocoupling product in this reaction condition, benzene would not be oxidized to phenyl radical species. This is also supported by the fact that the $\mathrm{C}-\mathrm{H}$ bond activation energy ${ }^{19 a}$ of benzene $\left(440 \mathrm{~kJ} \mathrm{~mol}^{-1}\right.$ as shown in Table S1) is much higher than that of acetonitrile (406 kJ $\mathrm{mol}^{-1}$ ).

Table 5 Results of the photocatalytic reaction tests for the cyanomethylation of benzene with acetonitrile over the photocatalyst samples and some mixtures. ${ }^{a}$

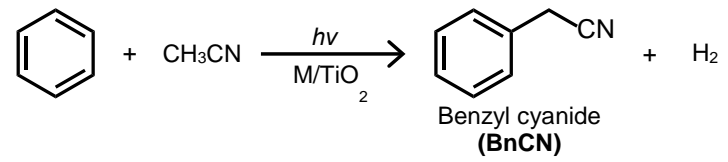

Byproducts:

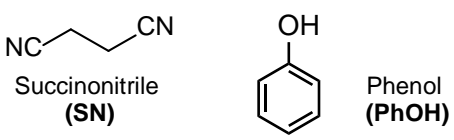

\begin{tabular}{|c|c|c|c|c|c|}
\hline \multirow[t]{2}{*}{ Entry } & \multirow[t]{2}{*}{ Catalyst $b$} & \multicolumn{4}{|c|}{ Products $/ \mu \mathrm{mol}$} \\
\hline & & $\mathrm{BnCN}$ & $\mathrm{PhOH}$ & $\mathrm{SN}$ & $\mathrm{H}_{2}$ \\
\hline 1 & $\mathrm{Pt} / \mathrm{TiO}_{2}$ & 0.08 & 0.91 & 12 & 20 \\
\hline 2 & $\mathrm{Pd} / \mathrm{TiO}_{2}$ & 4.0 & 1.6 & 1.1 & 10 \\
\hline 3 & $\mathrm{TiO}_{2}$ & n.d..$^{c}$ & n.d. & $\operatorname{tr}^{d}$ & 1.1 \\
\hline 4 & $\begin{array}{l}\mathrm{Pt} / \mathrm{TiO}_{2}+ \\
\mathrm{Pd}(0.1) / \mathrm{Al}_{2} \mathrm{O}_{3} e\end{array}$ & 0.40 & 0.35 & 9.4 & 13 \\
\hline 5 & $\begin{array}{l}\mathrm{Pt} / \mathrm{TiO}_{2}+ \\
\mathrm{Pd}(1.0) / \mathrm{Al}_{2} \mathrm{O}_{3} e\end{array}$ & 4.4 & 0.89 & 2.8 & 3.7 \\
\hline 6 & $\begin{array}{l}\mathrm{Pt} / \mathrm{TiO}_{2}+ \\
\mathrm{Pd}(2.0) / \mathrm{Al}_{2} \mathrm{O}_{3} e\end{array}$ & 4.6 & 1.8 & 0.81 & 1.0 \\
\hline 7 & $\mathrm{Pt} / \mathrm{TiO}_{2}+\mathrm{Al}_{2} \mathrm{O}_{3} e$ & 0.08 & 0.43 & 5.8 & 15 \\
\hline 8 & $\mathrm{Pd}(1.0) / \mathrm{Al}_{2} \mathrm{O}_{3}$ & n.d. & n.d. & n.d. & n.d. \\
\hline
\end{tabular}

a Reaction condition: The photocatalyst $0.20 \mathrm{~g}$, benzene $1.1 \mathrm{mmo}$ $(0.10 \mathrm{~mL})$, acetonitrile $72 \mathrm{mmol}(3.8 \mathrm{~mL})$, and water $5.6 \mathrm{mmol}(0.10$ $\mathrm{mL})$. Other conditions were the same as those described in the caption of Table 1. ${ }^{b}$ The loading amount of $\mathrm{Pt}$ or $\mathrm{Pd}$ on the $\mathrm{TiO}_{2}$ photocatalyst was $0.1 \mathrm{wt} \%$ and on the $\mathrm{Al}_{2} \mathrm{O}_{3}$ support was $0,0.1,1.0$, or $2.0 \mathrm{wt} \%{ }^{c}{ }^{c}$ Not detected. ${ }^{d}$ trace. ${ }^{e} \mathrm{~A}$ mixture of the $\mathrm{Pt} / \mathrm{TiO}_{2}$ sample of $0.20 \mathrm{~g}$ and the $\mathrm{Pd} / \mathrm{Al}_{2} \mathrm{O}_{3}$ sample of $0.20 \mathrm{~g}$ was used.

On the other hand, it is notable that the reaction over the $\mathrm{Pt} / \mathrm{TiO}_{2}$ sample gave a very small amount of $\mathrm{BnCN}$ with a large amount of $\mathrm{SN}$ 
(Table 5, entry 1), which means this photocatalyst would be active at least for the generation of the cyanomethyl radical. The pristine $\mathrm{TiO}_{2}$ sample scarcely produced the coupling products (Table 5 , entry 3 ), indicating that the metal nanoparticles enhanced the photocatalytic reaction. As mentioned above, it is generally accepted that metal nanoparticles can function as the electron receiver to enhance the charge separation, and $\mathrm{Pt}$ nanoparticles is one of the most typical electron receiver. In fact, the $\mathrm{Pt} / \mathrm{TiO}_{2}$ sample was more active than the $\mathrm{Pd} / \mathrm{TiO}_{2}$ sample for the cyanomethylation of aliphatic hydrocarbons. However, the $\mathrm{Pt} / \mathrm{TiO}_{2}$ sample promoted very slowly the cyanomethylation of benzene with acetonitrile, which is also well consistent with the previous study. ${ }^{10}$ Although the cyanomethyl radical was produced by the both catalysts, $\mathrm{BnCN}$ as the crosscoupling product was obtained only with the $\mathrm{Pd} / \mathrm{TiO}_{2}$ sample, but hardly obtained with the $\mathrm{Pt} / \mathrm{TiO}_{2}$ sample. The $\mathrm{Pd}$ nanoparticles would play a special role in the reaction. Since the particle size of Pt (2.1 $\mathrm{nm})$ and $\mathrm{Pd}(2.2 \mathrm{~nm})$ on $\mathrm{TiO}_{2}$ photocatalysts were almost same (Table S3, entries 1 and 2), the different performance of the photocatalyst should originate from the properties of the metals. Thus, it was suggested that the Pd nanoparticles would be necessary to catalyse at least one step in the cyanomethylation of benzene, which would be the reaction between benzene and cyanomethyl radical as a dark process. It was also revealed that this hybrid catalyst consisting the Pd metal catalyst and the $\mathrm{TiO}_{2}$ photocatalyst could be applied to other aromatic compounds such as toluene and pyridine as reported in the previous study, ${ }^{10}$ implying that the $\mathrm{Pd} / \mathrm{TiO}_{2}$ hybrid catalyst would promote the cyanomethylation of aromatic ring of these compounds.

In the present study, further experiments were carried out to confirm the assumption that the reaction between benzene and cyanomethyl radical requires the Pd nanoparticles as a catalyst. If the $\mathrm{Pd}$ nanoparticles catalysed the reaction of benzene with cyanomethyl radical, $\mathrm{BnCN}$ would be obtained even in the coexistence of the $\mathrm{Pd} / \mathrm{Al}_{2} \mathrm{O}_{3}$ sample as a supported metal catalyst and the $\mathrm{Pt} / \mathrm{TiO}_{2}$ sample as a photocatalyst for radical formation. The results are listed in Table 5, entries 4-6. Whereas the amount of $\mathrm{BnCN}$ was negligible small in the absence of the $\mathrm{Pd} / \mathrm{Al}_{2} \mathrm{O}_{3}$ sample (Table 5, entry 1 ), $\mathrm{BnCN}$ was obtained with the $\mathrm{Pt} / \mathrm{TiO}_{2}$ photocatalyst and the $\mathrm{Pd} / \mathrm{Al}_{2} \mathrm{O}_{3}$ catalyst (Table 5, entries 4-6). In addition, the yield of $\mathrm{BnCN}$ was improved with the increase of the loading amount of $\mathrm{Pd}$ on the $\mathrm{Al}_{2} \mathrm{O}_{3}$ support, but it was not efficiently improved more than $1.0 \mathrm{wt} \%$ loading, although the formation of SN was suppressed with higher loading amount of $\mathrm{Pd}$ on the $\mathrm{Al}_{2} \mathrm{O}_{3}$ support. It is noted that the mixture of the $\mathrm{Pt} / \mathrm{TiO}_{2}$ sample and bare $\mathrm{Al}_{2} \mathrm{O}_{3}$ support gave very small amount of the products (Table 5 , entry 7 ). Hence, these results obviously support that the $\mathrm{Pd}$ nanoparticles catalyse the reaction between benzene and the cyanomethyl radical, which would be not a photocatalytic process but a catalytic process. The $\mathrm{Pd} / \mathrm{Al}_{2} \mathrm{O}_{3}$ sample itself did not give any product upon photoirradiation (Table 5, entry 8 ), confirming that the $\mathrm{Al}_{2} \mathrm{O}_{3}$ support could not function as a photocatalyst due to the large band gap and thus the $\mathrm{Pt} / \mathrm{TiO}_{2}$ photocatalyst was required to generate the cyanomethyl radical species.

The amount of the exposed metal atoms of the Pd nanoparticles on the $\mathrm{Al}_{2} \mathrm{O}_{3}$ support were evaluated by the $\mathrm{CO}$ adsorption experiment (Table S3). It was confirmed that the particle size of the $\mathrm{Pd}$ nanoparticles in the $\mathrm{Pd} / \mathrm{Al}_{2} \mathrm{O}_{3}$ samples were in the range of 2.3$4.6 \mathrm{~nm}$. It was found that the obtained amounts of BnCN shown in Table 5 were almost consistent with the amount of exposed metal atoms, where turnover frequency (TF) calculated from the values were almost the same level in the range of $0.10-0.15 \mathrm{~h}^{-1}$. It is suggested that the surface $\mathrm{Pd}$ atom is the active sites for the catalytic step, the reaction between benzene and cyanomethyl radical, during the photocatalytic cyanomethylation of benzene.

In order to clarify the catalytic property of the Pd nanoparticles furthermore, temperature controlled reaction tests by using a water bath were performed over the $\mathrm{Pd} / \mathrm{TiO}_{2}$ sample. In these reaction tests, a reaction mixture of benzene $(0.1 \mathrm{~mL})$ and acetonitrile $(3.9$ $\mathrm{mL}$ ) was employed without the addition of the small amount of water in order to achieve the similar selectivity to that in the standard condition, since unfavourable by-products such as phenol were found at higher temperature. It is expected that the yield of $\mathrm{BnCN}$ will increase with the temperature if the Pd nanoparticles supported on the $\mathrm{TiO}_{2}$ photocatalyst can function as a metal catalyst. As a result, the $\mathrm{BnCN}$ yield increased with increasing the reaction temperature, but the $\mathrm{SN}$ yield did not increase so much as shown in Fig. 5 . The apparent activation energy calculated from the pseudo Arrhenius plot for the formation of $\mathrm{BnCN}$ was $43 \mathrm{~kJ} \mathrm{~mol}^{-1}$, which seems high enough as the value for a thermal catalytic process to produce BnCN. This step would be the rate determining step among the thermal processes, which should be catalysed by the Pd metal catalyst loaded on the $\mathrm{TiO}_{2}$ support. This step would correspond to the additionelimination step between benzene and cyanomethyl radical proposed in the previous study. ${ }^{10}$

The KIE of this reaction over the $\mathrm{Pd} / \mathrm{TiO}_{2}$ sample suggests that the $\mathrm{C}-\mathrm{H}$ bond dissociation of benzene to from benzene radical is not involved for the production of $\mathrm{BnCN} .{ }^{10}$ Therefore, it can be explained that the Pd thermal catalyst promotes the reaction of molecular benzene with the cyanomethyl radical to produce $\mathrm{BnCN}$ and hydrogen radical, i.e., the formation of the transition state having a $\mathrm{sp}^{3}$ carbon in the benzene ring and then the homolytic dissociation of the $\mathrm{C}-\mathrm{H}$ bond of the aromatic ring in the transition state. If the electron rich $\mathrm{Pd}$ metal nanoparticles ${ }^{14}$ donates the electron density to $\pi^{*}$ orbital of benzene, the molecular benzene would be activated before the reaction with the cyanomethyl radical. On one hand, the $\mathrm{Pd}$ nanoparticles are also expected to accelerate the $\mathrm{C}-\mathrm{H}$ bond homolytic dissociation of the aromatic ring of the transition state.

In contrast, the apparent activation energy for the formation of $\mathrm{SN}$ was $5.5 \mathrm{~kJ} \mathrm{~mol}^{-1}$ that would be acceptable as the activation energy for the photocatalytic reaction, ${ }^{20}$ suggesting that $\mathrm{SN}$ was formed by a photocatalysis through the homo-coupling of the cyanomethyl radicals.

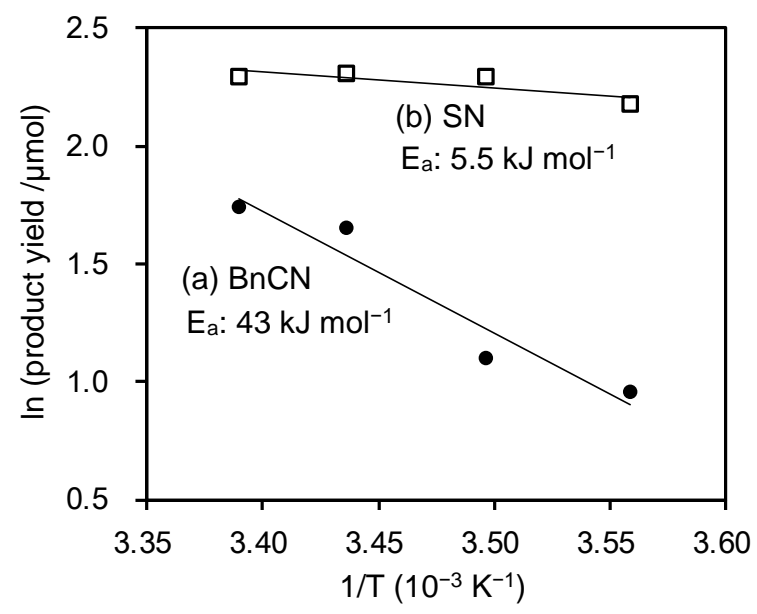

This journal is (C) The Royal Society of Chemistry 20xx 
Fig. 5 Pseudo Arrhenius plots of (a) benzyl cyanide (BnCN) and (b) succinonitrile $(\mathrm{SN})$ yields with the $\mathrm{Pd} / \mathrm{TiO}_{2}$ hybrid catalyst. Reaction condition: The $\mathrm{Pd} / \mathrm{TiO}_{2}$ sample $0.20 \mathrm{~g}$, benzene $1.1 \mathrm{mmol}$ $(0.10 \mathrm{~mL})$, and acetonitrile $73 \mathrm{mmol}(3.9 \mathrm{~mL})$. Reaction time was $2 \mathrm{~h}$. The irradiation condition was the same as that described in the caption of Table 1.

Therefore, the reaction mechanism of the cyanomethylation of benzene over the $\mathrm{Pd} / \mathrm{TiO}_{2}$ hybrid catalyst should be concluded as presented in Fig. 6 . The hole generates on the $\mathrm{TiO}_{2}$ photocatalyst under photoirradiation and oxidizes acetonitrile to form the cyanomethyl radical and proton, which is the RDS in the whole catalytic cycle of the reaction in the current condition. ${ }^{10}$ The cyanomethyl radical can react with the adsorbed and activated benzene on the $\mathrm{Pd}$ nanoparticles to form the complex having $\mathrm{sp}^{3}$ carbon in the transition state, as shown in Fig. 6 . The $\mathrm{C}-\mathrm{H}$ bond dissociation at the $\mathrm{Sp}^{3}$ carbon in the transition state is promoted on the Pd nanoparticles, followed by the formation of $\mathrm{BnCN}$ with releasing a hydrogen radical. This hydrogen radical and the photocatalytically formed radical can form a hydrogen molecule. It is clear that the formation of $\mathrm{BnCN}$ is one photon process.

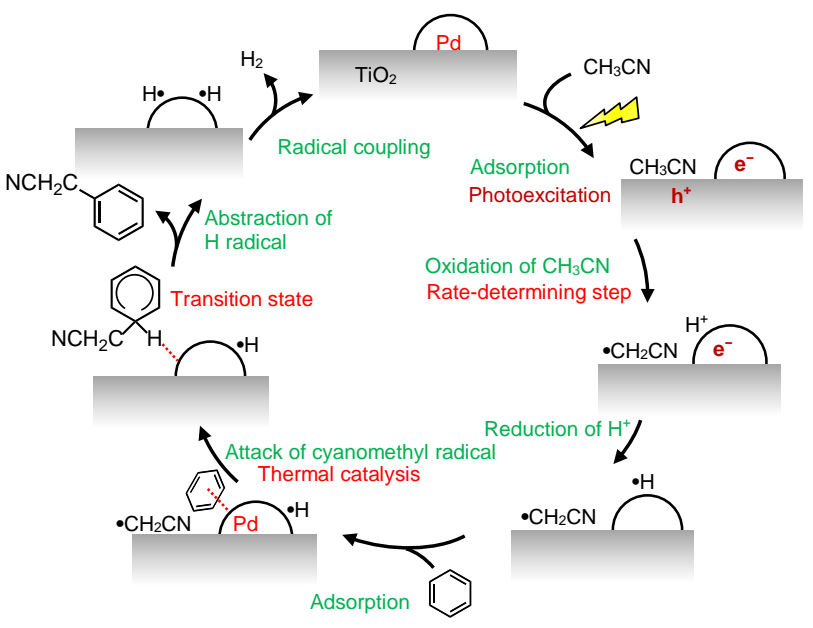

Fig. 6 Proposed photocatalysis and addition-elimination mechanism for the cyanomethylation of benzene over the $\mathrm{Pd} / \mathrm{TiO}_{2}$ hybrid catalyst.

\subsection{The role of the Pd nanoparticles}

Both of the $\mathrm{Pt} / \mathrm{TiO}_{2}$ and $\mathrm{Pd} / \mathrm{TiO}_{2}$ samples promoted the cyanomethylation of cyclohexane and cyclohexene (Table 1, entries 1-2, and Table 3, entries 1-2) via radical cross-coupling reaction. The addition of the $\mathrm{Pd} / \mathrm{Al}_{2} \mathrm{O}_{3}$ samples to these reaction systems did not improve the cyanomethylation reactions (Table 1, entries 4-6 and Table 3, entry 4), which means that the catalysis by the Pd metal nanoparticles was not required in these cases. Hence, it can be concluded that the cyanomethylation of cyclohexane and cyclohexene are mainly promoted by the photocatalysis with the $\mathrm{M} / \mathrm{TiO}_{2}$ samples, but the metal catalysis would not contribute to the reaction so much. In these reactions, the Pd nanoparticles would contribute as an acceptor of photoexcited electron to prolong the life time of the photoexcited charge carriers and enhance the radical formation, like as the Pt cocatalyst mentioned above.

However, the Pd metal catalyst was necessary for the photocatalytic cyanomethylation of benzene with acetonitrile. This would be related to the high $\mathrm{C}-\mathrm{H}$ bond dissociation energy for benzene molecule. This reaction was well promoted by the $\mathrm{Pd} / \mathrm{TiO}_{2}$ hybrid catalyst (Table 5 , entry 2 ) as well as the physical mixture of the $\mathrm{Pt} / \mathrm{TiO}_{2}$ photocatalyst and the $\mathrm{Pd} / \mathrm{Al}_{2} \mathrm{O}_{3}$ catalyst (Table 5 , entries 4-6). This fact evidenced that the supported Pd nanoparticles can function as the catalyst for at least one step during the cyanomethylation of benzene. The Pd nanoparticles would accelerate the addition-elimination step, i.e., the substitution reaction with cyanomethyl radical. On the other hand, it is also considered that the $\mathrm{Pd}$ nanoparticles deposited on the $\mathrm{TiO}_{2}$ photocatalyst would also contribute as the electron acceptor for the photoexcited electrons to improve the photocatalysis for the formation of the cyanomethyl radical.

In the past studies, the photocatalytic reactions for aromatic functionalization such as amination of benzene ${ }^{11}$ and hydroxylation of benzene ${ }^{12}$ were well promoted by $\mathrm{Pt} / \mathrm{TiO}_{2}$ photocatalyst without the Pd metal catalyst. In these reactions, ammonia and water molecules are oxidized to the radical species by the photogenerated holes and the substitution reaction of benzene with these radical species would proceed to form the product and hydrogen radical species without the Pd metal catalyst. This would be because these radical species would have enough reactivity toward a molecular benzene. On the other hand, the cyanomethyl radical might be more stable and less reactive than these radical species such as the surface hydroxyl radical and the amide radical, since the cyano group in the cyanomethyl radical would withdraw the electron from the radical centre to delocalise the radical property. Therefore, in the photocatalytic cyanomethylation of benzene with acetonitrile, the assist by the Pd catalyst would be necessary to promote the substitution process of benzene by the cyanomethyl radical species. Here, the Pd catalyst would activate benzene ring by adsorption before the cyanomethyl radical attack and assist the hydrogen abstraction from the intermediate. The Pd catalyst was not required for the cyanomethylation proceeding via radical coupling, as such the cyanomethylation of aliphatic hydrocarbons with acetonitrile, because the reactants can be oxidized to the radical species having enough reactivity for the radical coupling in nature. The assist by the Pd metal catalyst would be effective only for the addition-elimination process between aromatic ring and somewhat stable radical species such as cyanomethyl radical.

\section{Conclusions}

The direct cyanomethylation of cyclohexane and cyclohexene with acetonitrile by metal loaded photocatalysts proceeds via radical coupling reaction, where the reaction takes place photocatalytically even without the aid of $\mathrm{Pd}$ metal catalysis. In these cases, the $\mathrm{Pt}$ and $\mathrm{Pd}$ nanoparticles on the $\mathrm{TiO}_{2}$ photocatalyst would contribute as just an acceptor of photoexcited electrons to enhance the photocatalytic reaction rate. These reactions are two photon processes.

In contrast, the $\mathrm{Pd} / \mathrm{TiO}_{2}$ hybrid catalyst or the physical mixture of the $\mathrm{Pt} / \mathrm{TiO}_{2}$ photocatalyst and the $\mathrm{Pd} / \mathrm{Al}_{2} \mathrm{O}_{3}$ catalyst are required to promote the reaction between benzene and acetonitrile, where the Pd nanoparticle functions as a metal catalyst for the reaction between benzene molecule and cyanomethyl radical species through the addition-elimination process before completing the cyanomethylation. In the cyanomethylation of benzene, the $\mathrm{Pd}$ nanoparticle on the $\mathrm{TiO}_{2}$ photocatalyst functions as not only an acceptor for the 
photoexcited electron but also a metal catalyst. Thus, the Pd nanoparticle is bifunctional cocatalyst. This is a one photon process.

In this study, some rules in the photocatalytic organic reactions were suggested, i.e., both of the reactivity of reactant to become the corresponding radical species and the reactivity of the radical species should be the important factors for the determination of the reaction rate and the product selectivity, and the metal nanoparticles can help these reaction steps as an electron acceptor or a metal catalyst to promote the photocatalytic coupling reactions. These simple photocatalytic coupling reaction systems would widely provide desirable applications in the field of chemical synthesis in view of green and sustainable chemistry.

\section{Experimental Section}

\subsection{Preparation of metal loaded $\mathrm{TiO}_{2}$ and $\mathrm{Al}_{2} \mathrm{O}_{3}$}

Anatase $\mathrm{TiO}_{2}$ (JPC-TIO-8, $338 \mathrm{~m}^{2} \mathrm{~g}^{-1}$ ) supplied by Catalysis Society of Japan was used as the photocatalyst. Metal nanoparticles were loaded by a photodeposition method as below. $\mathrm{TiO}_{2}$ powder was suspended in distilled water in a beaker and irradiated by the light from a $300 \mathrm{~W}$ xenon lamp (PE300BUV) without any optical filters (the intensity was $50 \mathrm{~mW} \mathrm{~cm}-2$ measured at $360 \pm 15 \mathrm{~nm}$ ) to clean the catalyst surface for $60 \mathrm{~min}$. After the pre-irradiation, a stock solution of a metal precursor ( $\mathrm{PdCl}_{2}$, Wako $99.0 \%$, dissolved in an aqueous solution of $\mathrm{HCl}$, or $\mathrm{H}_{2} \mathrm{PtCl}_{6}$, Wako $99.8 \%$, dissolved in water) and 20 vol\% of methanol as a hole scavenger were added into the suspension, and then it was stirred for $15 \mathrm{~min}$ in the dark, followed by photoirradiation from the xenon lamp without optical filters for $60 \mathrm{~min}$. The obtained sample was separated from the suspension by suction filtration and washed with distilled water. The prepared sample was dried at $323 \mathrm{~K}$ overnight in an electric oven to obtain the metal loaded photocatalyst, i.e., the $\mathrm{M} / \mathrm{TiO}_{2}$ samples. The metal loading amount of $\mathrm{Pd}$ or Pt was $0.1 \mathrm{wt} \%$.

An impregnation method was employed for the preparation of the metal loaded $\mathrm{Al}_{2} \mathrm{O}_{3}$ samples. The $\mathrm{Al}_{2} \mathrm{O}_{3}$ spherical granule donated by Catalysis Society of Japan (JRC-ALO-07, $204 \mathrm{~m}^{2} \mathrm{~g}^{-1}$ ) was milled with a mortar before use. The $\mathrm{Al}_{2} \mathrm{O}_{3}$ powder, distilled water, and an aqueous solution of the metal precursor mentioned above were put into a beaker followed by stirring for $60 \mathrm{~min}$ at room temperature. The mixture was heated for evaporation to dryness around $373 \mathrm{~K}$ with stirring, and the obtained powder was calcined at $723 \mathrm{~K}$ for 60 min. The obtained powder samples were referred to as the $\mathrm{M}(x) / \mathrm{Al}_{2} \mathrm{O}_{3}$ samples, where the metal loading amount $(x)$ on the $\mathrm{Al}_{2} \mathrm{O}_{3}$ support was $0.1,1.0$ or $2.0 \mathrm{wt} \%$.

\subsection{Reaction tests}

The photocatalytic reaction tests were typically carried out in the following manner. The $\mathrm{M} / \mathrm{TiO}_{2}$ sample $(0.2 \mathrm{~g})$ was put into the quartz reactor $\left(46 \mathrm{~cm}^{3}\right)$ and pre-irradiated from the beneath $\left(20 \mathrm{~cm}^{2}\right)$ with the xenon lamp for $15 \mathrm{~min}$ in air to clean the catalyst surface. After purging with argon, a mixture consisting of $0.1 \mathrm{~mL}$ of benzene, cyclohexane or cyclohexene, $3.8 \mathrm{~mL}$ of acetonitrile and $0.1 \mathrm{~mL}$ of distilled water, were introduced into the reactor. All reactants for the reaction tests were of analytical grade reagents and used without further purification. The reaction test was carried out under the light of $365 \pm 20 \mathrm{~nm}$ in wavelength from the xenon lamp for $60 \mathrm{~min}$ with cooling by an electric fan. The light intensity was measured at $360 \pm 15$ $\mathrm{nm}$ to be $27 \mathrm{~mW} \mathrm{~cm}^{-2}$. After the reaction, the products in the gas phase were collected by a gas tight syringe and then analysed by a GC-TCD (Shimadzu, GC-8A). The reaction mixture was diluted with methanol and filtrated with a PTFE filter. The filtrate was mixed with a methanol solution of $n$-decane as an internal standard, and then analysed by a GC-MS (Shimadzu, GCMS-QP5050A).

\subsection{Electron spin resonance (ESR) measurement}

In order to investigate the radical species formed during the cyanomethylation of cyclohexane and cyclohexene, ESR spectra were recorded by an X-band spectrometer (JEOL-RE2X) in the presence of the $\mathrm{Pd} / \mathrm{TiO}_{2}$ photocatalyst under photoirradiation. Before the measurement, the $\mathrm{Pd} / \mathrm{TiO}_{2}$ sample was pre-irradiated for $60 \mathrm{~min}$ in order to clean the sample surface. The trace amount of the pre-irradiated $\mathrm{Pd} / \mathrm{TiO}_{2}$ sample $(0.02 \mathrm{~g})$ was suspended in cyclohexane or cyclohexene (1 mL; $9.3 \mathrm{mmol}$ and $9.8 \mathrm{mmol}$, respectively) with PBN (N-tert-Butyl- $\alpha$-phenylnitrone, Tokyo Chemical Industry, 98\%, $0.67 \mathrm{mmol}$ ) as a spin trap reagent, then a part of the solution was taken into a quartz sample cell. In order to suppress the photodissociation of the cyclohexane and cyclohexene, the light from a xenon lamp was limited to $400 \pm 20 \mathrm{~nm}$ in wavelength with a band-pass filter. Especially, for measuring the ESR spectra of the cyclohexene solution, oxygen was carefully removed from the mixed solution of cyclohexene and PBN, and then a part of the solution was transferred into a quartz sample cell. After that, a trace amount of the $\mathrm{Pd} / \mathrm{TiO}_{2}$ sample was added into the solution, followed by argon purge. Other procedure and condition were the same as mentioned above.

\section{4. $\mathrm{CO}$ adsorption}

The size of $\mathrm{Pd}$ and $\mathrm{Pt}$ nanoparticles loaded on the $\mathrm{TiO}_{2}$ and $\mathrm{Al}_{2} \mathrm{O}_{3}$ were measured by using a $\mathrm{CO}$ pulse method. The catalyst samples used was $50 \mathrm{mg}$. As a pretreatment, metal loaded $\mathrm{TiO}_{2}$ samples were heated at $473 \mathrm{~K}$ for $15 \mathrm{~min}$ in a flow of hydrogen (11\%) and argon mixture before measurements, while metal loaded $\mathrm{Al}_{2} \mathrm{O}_{3}$ samples were heated at $673 \mathrm{~K}$ in the same condition. The $\mathrm{CO}$ gas was detected by GC-TCD (Shimadzu, GC-8A). Metal dispersion and particle size were calculated from the adsorption amount of $\mathrm{CO}$.

\section{Acknowledgements}

This work was supported by JSPS KAKENHI Grant Numbers 25105723, and 16J03722. The authors thanks to Dr. H. Yuzawa at Institute for Molecular Science for valuable comments.

\section{Notes and references}

1 Y. Kawano, N. Kaneko, and T. Mukaiyama, Chem. Lett., 2005, 34, 1508.

2 (a) R. Shang, D.-S. Ji, L. Chu, Y. Fu and L. Liu, Angew. Chem., Int. Ed., 2011, 50, 4470; (b) P. Y. Yeung, K. H. Chung and F. Y. Kwong, Org. Lett., 2011, 13, 2912.

3 M. E. Kurz, S. C. Lapin, K. Mariam, T. J. Hagen, and X. Q. Qian, Org. Chem., 1984, 49, 2728.

4 S. Chakraborty, Y. J. Patel, J. A. Krause, and H. Guan, Angew. Chem., Int. Ed., 2013, 52, 7523.

5 J. Zhang, W. Wu, X. Ji and S. Cao, RSC Adv., 2015, 5, 20562.

6 Y. Liu, K. Yang, and H. Ge, Chem. Sci., 2016, 7, 2804. 
7 J. Velcicky, A. Soicke, R. Steiner, and H. G. Schmalz, J. Am. Chem. Soc., 2011, 133, 6948.

8 (a) C. Pan, H. Zhang and C. Zhu, Org. Biomol. Chem., 2015, 13, 361; (b) A. Bunescu, Q. Wang, and J. Zhu, Angew. Chem. Int. Ed. 2015, 54, 3132; (c)J. Li, Z. Wang, N. Wu, G. Gao, and J. You, Chem. Commun., 2014, 50, 15049.

9 G.C. Bond, G. Webb, P.B. Wells, and J.M. Winterbottom, J. Catal., 1962, 1, 74.

10 H. Yoshida, Y. Fujimura, H. Yuzawa, J. Kumagai, and T. Yoshida, Chem. Commun., 2013, 49, 3793.

11 H. Yuzawa, S. Yoneyama, A. Yamamoto, M. Aoki, K. Otake, H. Itoh and H. Yoshida, Catal. Sci. Technol., 2013, 3, 1739.

12 (a) H. Yoshida, H. Yuzawa, M. Aoki, K. Otake, H. Itoh, and T. Hattori, Chem. Commun., 2008, 38, 4634; (b) H. Yuzawa, M. Aoki, K. Otake, T. Hattori, H. Itoh, and H. Yoshida, J. Phys. Chem. C, 2012, 116, 25376.

13 (a) H. Yuzawa, and H. Yoshida, Chem. Commun., 2010, 46, 8854. (b) H. Yuzawa, J. Kumagai, and H. Yoshida, J. Phys. Chem. C, 2013, 117, 11047.

14 A. Tyagi, T. Matsumoto, T. Kato, and H. Yoshida, Catal. Sci. Technol., 2016, 6, 4577.

15 (a) A. J. Bard, Science, 1980, 207, 139; (b) H. Yuzawa, T. Mori, H. Itoh, and H. Yoshida, J. Phys. Chem. C, 2012, 116, 4126.

16 (a)K. Selevam, H. Sakamoto, Y. Shiraishi, and T. Hirai, New J. Chem., 2015, 39, 2856; (b) B. Ohtani, K. Iwai, S. I. Nishimoto, and S. Sato, J. Phys. Chem. B, 1997, 101, 3349.

17 S. Nishimoto, B. Ohtani, and T. Kagiya, J. Chem. Soc., Faraday Trans., 1985, 1, 81, 2467.

18 L. J. Libertini and O.H. Griffith, J. Chem. Phys., 1970, 53, 1359.

19 (a) Y-R. Luo, Handbook of bond dissociation energies in organic compounds, CRS press, 2007. (b) Z. Tian, A. Fattahi, L. Lis, and S.R. Kass, J. Am. Chem. Soc., 2006, 128, 17087.

20 (a) R. J. Davis, J. L. Gainer, G. O'Neal, and I. W. Wu, Water Environ. Res., 1994, 66, 50; (b) L. Minsker, C. Pulgarin, P. Peringer, and J. Kiwi, New J. Chem., 1994, 18, 793; (c) A.V. Vorontsov, E.N. Savinov, G.B. Barannik, V.N. Froitsky, and V.N. Parmon, Catal. Today, 1997, 39, 207; (d) K. Shimura, K. Maeda, and H. Yoshida, J. Phys. Chem. C, 2011, 115, 9041. 